\title{
The Numerical Simulation of Pipe/Soil Interaction Under Wave Loadings
}

\author{
Ren Yanrong ${ }^{1, *}$ and Liu Yubiao ${ }^{2}$ \\ ${ }^{I}$ Science School, Beijing Institute of Civil Engineering and Architecture, Beijing 100044, China \\ ${ }^{2}$ Institute of Mechanics, Chinese Academy of Sciences, Beijing100080, China
}

\begin{abstract}
The on-bottom stability of submarine pipeline is a key problem of submarine pipeline design.The key issue is to simulate the interaction among wave,pipe and soil. In this paper, the constitutive models of soil, such as nonlinear elastic, porous elastic and Ramberg-Osgood models are adopted respectively, and the pipe/soil interaction has been analyzed by the common finite element software ABAQUS program. The contact surfaces have been established. The factors such as contact effect,frictional coefficient between pipe and soil ,pipe's penetration, the impact of yielding stress are considered. Also, the results show that the computation of the pipe/soil interaction is feasible and may provide a helpful tool for the engineering practice of pipeline on-bottom stability design.
\end{abstract}

Keywords: Submarine pipeline, sandy seabed, pipe/soil interaction, numerical simulation.

\section{INTRODUCTION}

The on-bottom stability of submarine pipeline is a key problem of submarine pipeline design. If the sea bottom can not provide enough lateral resistance to balance the horizontal component of the hydrodynamic force, the pipeline breakout will take place,i.e. instability occurs.

Since 1980's, many foreign scientific institutes [1-5] have conducted the further research to the pipe/soil interaction of the untrenched pipe by the cyclic loading. The main conclusions are: the hydrodynamic force induced by wave and current can lead to the pipe's additional penetration, and the soil lateral moundings beneath the pipe will take place when the pipe's lateral displacement happens, these will cause that the soil's lateral resistance is larger than Coulomb friction force, so the lateral resistance coefficient larger than Coulomb friction coefficient.

They also put forward the pipe/soil interaction model, as shown in Fig. (1). In this model, the soil resistance should include a soil passive resistance component as follows:

$F_{H}=F_{F}+F_{R}$

where $F_{H}$ is total lateral soil resistance, $F_{F}$ sliding resistance and $F_{R}$ lateral passive soil resistance. The above experimental results are reflected in the Veritect's and AGA's design guidelines [6,7].

Gu xiaoyun and Gao fuping $[8,9]$ have conducted the pipe/soil interaction experiment under the hydrodynamic force, discussed the physical mechanism definitely besides obtaining the similar results compared to the previous experiments, and also pointed out that the pipeline's instability of the wave-soil-pipe coupling effect is a result of combined

*Address correspondence to this author at the Science School, Beijing Institute of Civil Engineering and Architecture, Beijing 100044,China;

Tel: 86-13691383820; E-mail: wshuhe@sina.com

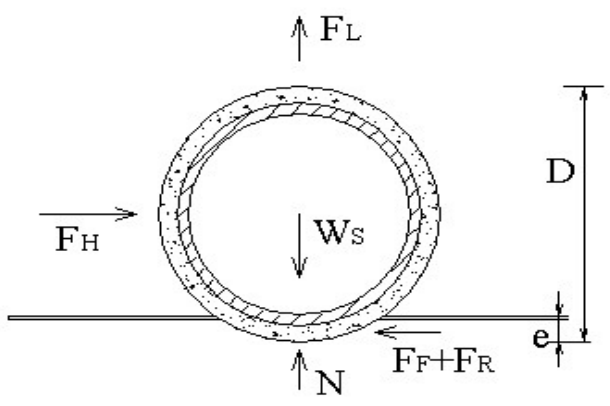

Fig. (1). Pipe/soil interaction.

action of vortex above the seabed and seepage under the sea bottom, that is to say that the permeability plays an important factor.

Lyons [10] has conducted the computation of the untrenched pipe, adopted nonlinear elastic model and static method. Mei [11] has studied the breakout of half-buried pipe under hydrodynamic force. Yongbai [12] has analyzed the on-bottom stability of submarine pipeline, but only concerned with the deformation action of the pipeline, not considering the pipe/soil interaction.

Gao fuping [13] has proposed an improved analysis method for the on-bottom stability of a submarine pipeline which is based on the relationship between $\mathrm{Um} / \mathrm{gD} 0.5$ and Ws/D2. The proposed analysis method may provide a helpful tool for the engineering practice of pipeline on-bottom stability design. Gao fuping [14] has employed a hydrodynamic loading method in a flow flume for simulating ocean currents induced submarine pipeline stability on a sandy seabed. The pipeline stability in currents is compared with that in waves, which indicates that the pipeline laid directly upon the sandy seabed is more laterally stable in currents than in waves. 
Table 1. Soil Characteristics for Duncan-Chang Nonlinear Elastic Model

\begin{tabular}{|c|c|c|c|c|c|c|c|c|}
\hline $\begin{array}{c}\text { Cohesion } \\
\boldsymbol{C}(\mathbf{k P a})\end{array}$ & $\begin{array}{c}\text { Angle of } \\
\text { Internal } \\
\text { Friction } \\
\boldsymbol{\phi ( \boldsymbol { ( } ^ { 0 } )}\end{array}$ & $\begin{array}{c}\text { Saturated } \\
\text { Density } \\
\boldsymbol{P}_{\text {sat }} \\
\left(\mathbf{k g} / \mathbf{m}^{3}\right)\end{array}$ & $\begin{array}{c}\text { Failure } \\
\text { Rate } \\
\boldsymbol{R}_{f}\end{array}$ & $\begin{array}{c}\text { Experimental } \\
\text { Constant } \\
\boldsymbol{K}\end{array}$ & $\begin{array}{c}\text { Experimental } \\
\text { Constant } \\
\boldsymbol{n}\end{array}$ & $\begin{array}{c}\text { Experimental } \\
\text { Constant } \\
\boldsymbol{G}\end{array}$ & $\begin{array}{c}\text { Experimental } \\
\text { Constant } \\
\boldsymbol{F}\end{array}$ & $\begin{array}{c}\text { Experimental } \\
\text { Constant } \\
\boldsymbol{D}\end{array}$ \\
\hline \hline 0.0 & 40 & $2.0 \times 10^{3}$ & 0.85 & 410 & 0.60 & 0.34 & 0.09 & 420 \\
\hline
\end{tabular}

Table 2. Soil Characteristics for Porous Elastic Model

\begin{tabular}{|c|c|c|c|c|c|}
\hline $\begin{array}{c}\text { Soil Porosity } \\
\boldsymbol{n}\end{array}$ & $\begin{array}{c}\text { Poisson's } \\
\text { Ratio } \\
\boldsymbol{\mu}\end{array}$ & $\begin{array}{c}\text { Shear Modulus } \\
\boldsymbol{G}\left(\mathbf{N} / \mathbf{m}^{2}\right)\end{array}$ & $\begin{array}{c}\text { Soil Permeability } \\
(\mathbf{m} / \mathbf{s e c})\end{array}$ & $\begin{array}{c}\text { Bulk Modulus of Soil } \\
\text { Particle } \\
\left(\mathbf{N} / \mathbf{m}^{2}\right)\end{array}$ & $\begin{array}{c}\text { Bulk Modulus of Soil } \\
\text { Skeleton } \\
\left(\mathbf{N} / \mathbf{m}^{2}\right)\end{array}$ \\
\hline \hline 0.4 & 0.4 & $5 \times 10^{6}$ & $\begin{array}{c}10^{-2} \text { (coarse sand) } \\
10^{-4} \text { (fine sand) }\end{array}$ & $40 \times 10^{9}$ & $100 \times 10^{6}$ \\
\hline
\end{tabular}

Table 3. Soil Characteristics for Ramberg-Osgood Model

\begin{tabular}{|c|c|c|c|c|}
\hline $\begin{array}{c}\text { Elastic Modulus } \\
\left(\mathbf{N} / \mathbf{m}^{2}\right)\end{array}$ & $\begin{array}{c}\text { Poisson's Ratio } \\
\boldsymbol{\mu}\end{array}$ & $\begin{array}{c}\text { Hard Parameter of Non- } \\
\text { linear Term } \\
\boldsymbol{n}\end{array}$ & $\begin{array}{c}\text { Shear Stress } \\
\boldsymbol{\tau}_{\mathbf{y}}(\mathbf{P a})\end{array}$ & $\begin{array}{c}\text { Yield Offset } \\
\mathbf{a}\end{array}$ \\
\hline \hline $5 \times 10^{5}$ & 0.35 & 5 & $3 \times 10^{4}$ & 1 \\
\hline
\end{tabular}

Table 4. Pipe Parameters

\begin{tabular}{|c|c|}
\hline $\begin{array}{c}\text { Elastic Modulus } \\
\left(\mathbf{N} / \mathbf{m}^{2}\right)\end{array}$ & $\begin{array}{c}\text { Poisson's Ratio } \\
\boldsymbol{u}\end{array}$ \\
\hline \hline $210 \times 10^{9}$ & 0.3 \\
\hline \hline
\end{tabular}

Liu Jing [15] has simulated the interaction among flow, pipe and soil. The factors such as contact effect, frictional coefficient between pipe and soil, buried depth, pipe radius. Based on the numerical results the vertical displacement and hoop stress should are underestimated dramatically without considering the contact effect in the case of smaller buried depth. Meanwhile, porous water pressure in coarse sand attenuates slower than that in fine sand, so pipe embedded in fine sand is more stable and safer than that in coarse sand.

In this paper, the pipe/soil interaction has been simulated by using the ABAQUS [16] software. The pipe/soil system has been assumed to be plane strain, and the pipe is elastic.

\section{COMPUTATION MODEL}

\subsection{Mathematical Formulation}

To choose the soil's constitutive model is an important factor in the geotechnical engineering. In this paper three different models are adopted. Such as Duncan-Chang nonlinear elastic, porous elastic, Ramberg-Osgood model. The mathematical formulation are as follows and parameters needed are shown in Table 1-5.

The Duncan-Chang nonlinear model is:

$$
v_{t}=\frac{G-F \lg \left(\frac{\sigma_{3}}{P a}\right)}{\left\{1-\frac{D\left(\sigma_{1}-\sigma_{3}\right)}{K P a\left(\frac{\sigma_{3}}{P a}\right)^{n}\left[1-\frac{R_{f}\left(\sigma_{1}-\sigma_{3}\right)(1-\sin \phi)}{2 c \cos \phi+2 \sigma_{3} \sin \phi}\right]}\right\}^{2}}
$$

In which: $C, \phi$-shear strength quota, $P a$-atmosphere pressure, $\sigma_{1}, \sigma_{3}$-axial principal stress, $K, R_{f}, n, G, F, D$ - undecided parameter

The porous elastic model is:

$$
\begin{aligned}
& \sigma_{x}^{\prime}=2 G\left(\frac{\partial u}{\partial x}+\frac{u}{1-2 u} \varepsilon\right) \\
& \sigma_{y}^{\prime}=2 G\left(\frac{\partial v}{\partial x}+\frac{u}{1-2 u} \varepsilon\right) \\
& \tau=G\left(\frac{\partial u}{\partial x}+\frac{\partial v}{\partial y}\right)
\end{aligned}
$$

In which: $\sigma_{x}$-soil skeleton's horizontal stress, $\sigma_{y}^{\prime}$-soil skeleton's vertical stress, $\tau-$ shear stress.

The Ramberg-Osgood model is:

$G_{0} \gamma=\tau+\alpha\left|\frac{\tau}{\tau_{y}}\right|^{n-1}$

In which: $G 0$-shear module, $Y$-shear stress, $\tau$-shear stress, $\tau_{y}$-yielding stess, $n$-nonlinear hardening parameter, $\alpha$ yielding offset.

Table 5. Wave Parameters

\begin{tabular}{|c|c|c|c|c|c|}
\hline Wave Period (s) & Water Depth $(\mathbf{m})$ & Wave Length $(\mathbf{m})$ & Wave Height $(\mathbf{m})$ & $\begin{array}{c}\text { Water Volume Module } \\
\left(\mathbf{N} / \mathbf{m}^{2}\right)\end{array}$ & $\begin{array}{c}\text { Seawater Density } \\
\left(\mathbf{k g} / \mathbf{m}^{2}\right)\end{array}$ \\
\hline \hline $10.0,12.5,15$ & $20,40,60$ & 121.1 & 5.0 & $2 \times 10^{9}$ & 1030 \\
\hline
\end{tabular}




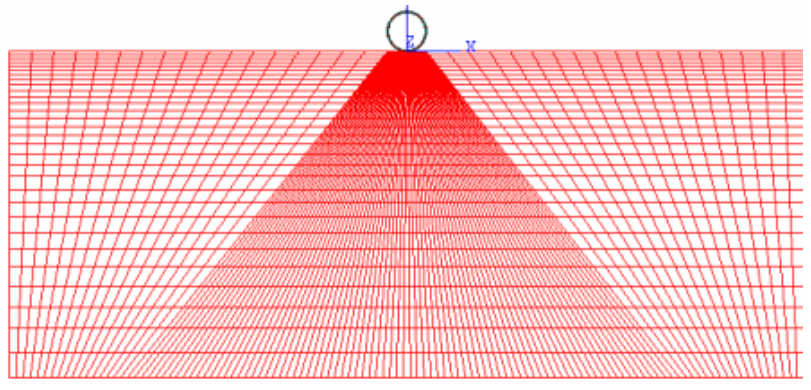

Fig. (2). Finite element model.

\subsection{The Determination of Wave Loadings}

Actually the pipeline is laid on the seabed, so the wave load is dynamic. The wave load is decided according to the Morsion equation.

$F_{H}=F_{D}+F_{l}$ force

In which: $F_{D}$-horizontal drag force, $F_{l}$-horizontal inertial

$F_{D}=\frac{C_{D}}{2} \rho D u_{x}\left|u_{x}\right|$

In which: $D$-pipe's diameter, $P$-fluid mass density, $C_{D^{-}}$ drag force coefficient, $1.25, u_{x \text {-The horizontal velocity }}$ commponent of water mass point

$F_{I}=C_{I} \frac{\rho \pi D^{2}}{4} \dot{u}_{x}$

In which, $C_{l}$-intertial coffecient, 2.0 .

\section{THE ESTABLISHMENT OF FINITE ELEMENT MODEL}

\subsection{Contact Problem}

In resolving the pipe/soil interaction, the shearing slip can occur between the contact surface pipe and seabed. In the contact simulation of ABAQUS, the simple master-slave contact method is adopted. In order to obtain better result, the slave and master surface must be chosen carefully, the discipline is: slave surface must be the surface of finer mesh; if mesh density is similar, slave surface must be composed of soft material. Based on the discipline, the lower pipe as master contact surface, two pipe's diameter length on the seabed is chosen to be the slave contact surface, in order to form a "contact pair".

\subsection{Finite Element Model and Boundary Conditions}

Because the seabed foundation is a semi-infinite space, the certain range should be chosen in the computation. When defining the size of the finite element computation model, the range of the finite element computation model is defined according to the following principles: horizontal direction the seabed is twenty times of pipe's diameter, vertical is ten times. In the computation, eight-node element is used for the pipe, the four-node element is used for the seabed, The finite element model is as shown in Fig. (2). Boundary conditions are as follows: far away from the pipeline, zero displacements at the both sides, the bottom, however, free boundary is used at the top.

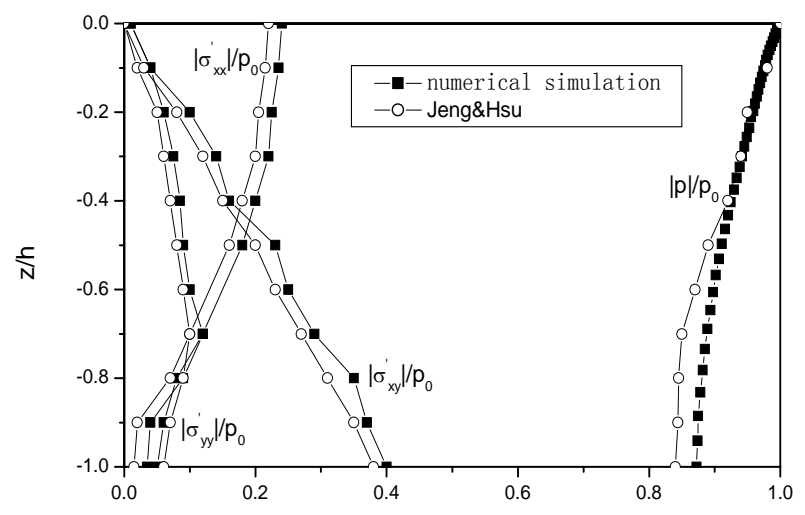

Fig. (3). The pore pressure and effective stress in coarse sand.

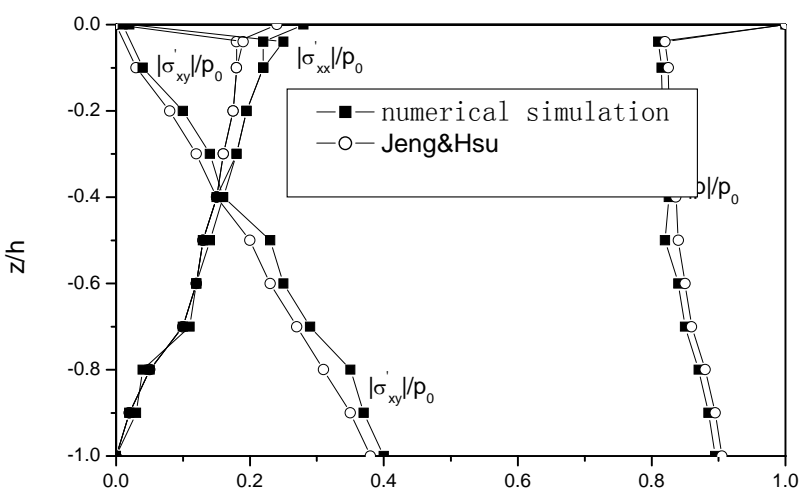

Fig. (4). The pore pressure and effectivestress in fine sand.

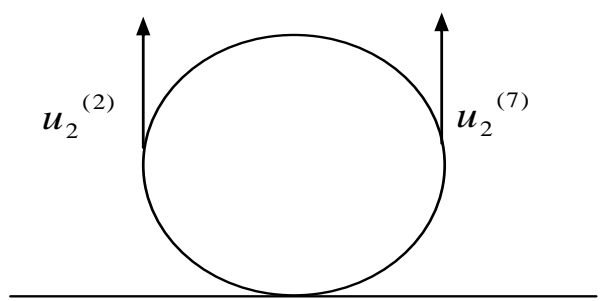

Fig. (5). Constraint equation.

In order to test the correction of the FE, we have conducted the free field response of the seabed under wave loadings. The results and graphs are as follows Figs. (3 and 4). Compared with the previous computation results, it can be found that the FE mesh is reasonable.

\subsection{Constraint Conditions}

Actually the pipeline is constrained by the riser and its rotation stiffness, so the pipe can not roll. But in two dimensional simulation, it is possibile for the pipeline to roll on the seabed. So the constraint equation is adopted at both sides of the pipeline in order to prevent the pipe from rolling, as shown in Fig. (5).

The constraint equation is as follows:

$u_{2}^{2}+(-1) u_{2}^{7}=0$

In which, 2 and 7 are the node number of both sides of the pipe separately. 


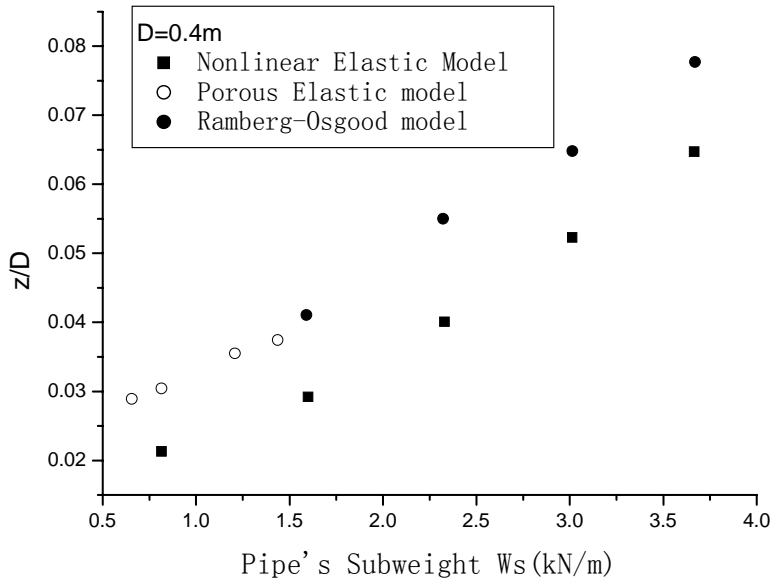

Fig. (6). The relationship between pipe's subweights.

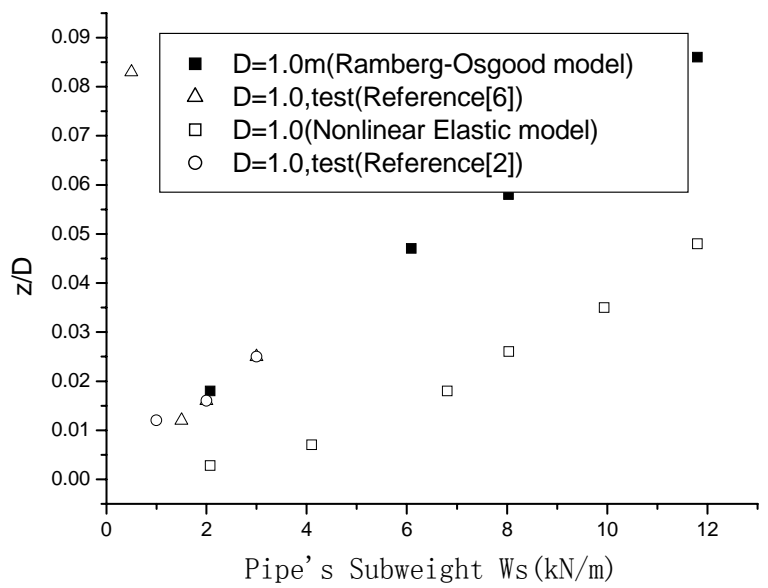

Fig. (7). The comparability of computed penetration and penetration experiment.

\section{COMPUTATION RESULTS}

\subsection{Static Computation Results}

The sand's friction coefficient is 0.7 when Lyons used static method. In this paper, when using static method, the lateral resistance coefficient is equal to the Coulomb friction coefficient of the contact face, which explains that our computation matches with the previous computation results. But as described before, the environmental loading is dynamic, and also the wave-pipe-soil coupling experiment has been conducted under the hydrodynamic force. So the followings are dynamic results.

\subsection{Pipe's Penetration}

From Fig. (6), it can be found that when the pipe's diameter is $0.4 \mathrm{~m}$, the penetration of pipe for the porous elastic model and Ramberg-Osgood model are identical, the nonlinear elastic model is smaller, but has no experimental data. From Fig. (7), the pipe's diameter is $1.0 \mathrm{~m}$, the RambergOsgood model's results are in accordance with the experiments, the nonlinear elastic model is smaller. This demonstrates that the porous elastic model and the RambergOsgood model are in accordance with the experiment in penetration, but the nonlinear elastic model is smaller.

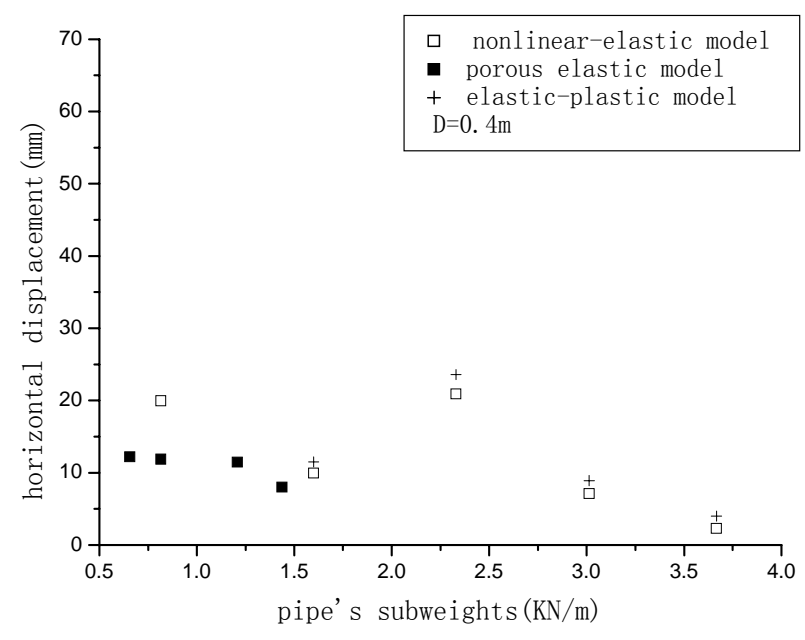

Fig. (8). The relationship between penetration and yielding stress.

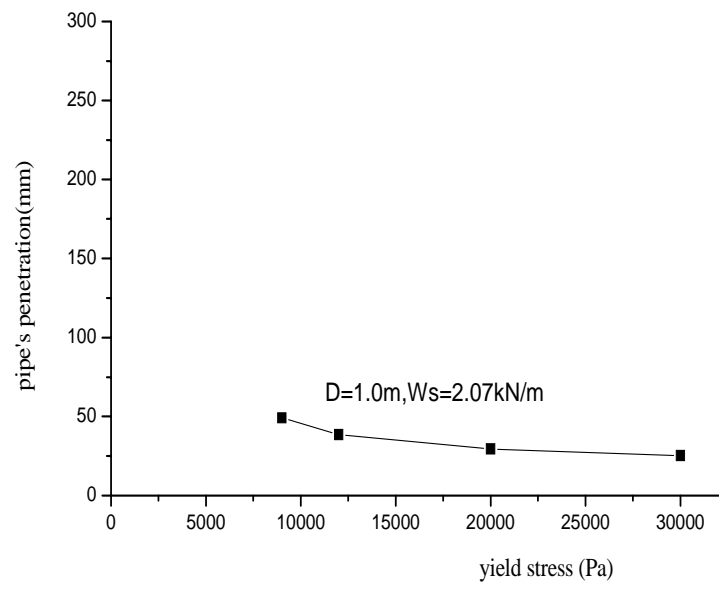

Fig. (9). The relationship between penetration and yield stress.

In which, $z$-pipe's penetration, $D$-pipe's diameter, $W_{s}$ submerged weight of pipe per unit length.

\subsection{The Relationship Between Pipe's Penetration and Horizontal Displacement}

From Fig. (8), it can be found that when adopting the elastic-plastic model, the horizontal displacement is larger than that of porous elastic model and nonlinear model.

\subsection{The Impact of Yield Stress}

For plastic model, if soil element's stress exceed yield stress, so the soil will achieve yield state and destruction occurs. The impact of yield stress has been considered (see Fig. 9).

From Fig. (9), The pipe's penetration is increasing with the decreasing of yield stress. This is because that the yield stress is smaller, the stress of soil element is easy to get to the yield point, so some part of soil are destroyed, and cause pipe's penetration to increase.

\subsection{Soil Lateral Mounding Phenomena}

D. W. Allen [17] had given the detail description for pipe's movement, the cyclic loading caused pipe penetration into the soil and soil mounding in front of the pipe, as shown 


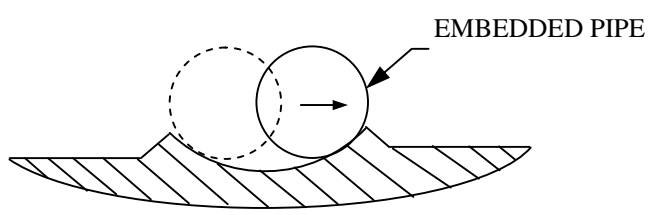

Fig. (10). Embedment of pipe in soft sediments.

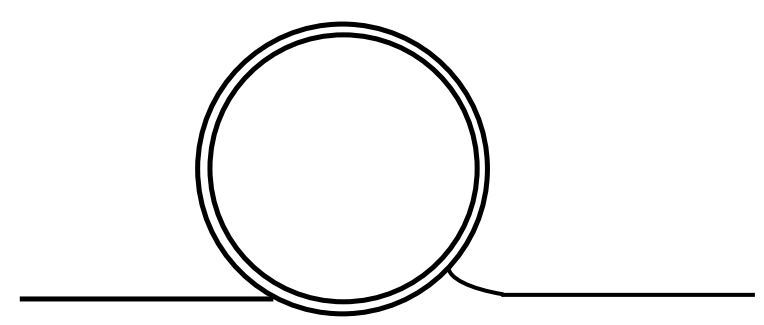

Fig. (11). The computed soil lateral moundings.

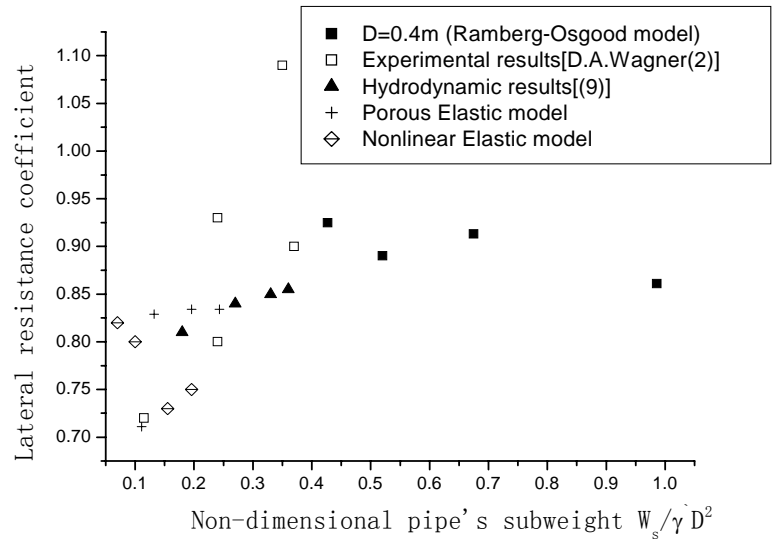

Fig. (12). The comparability of computed resistance coefficient and experimental results.

in Fig. (10). Our computation have obtained the similar phenomena, as shown in Fig. (11). But the extent of soil mounding of different model are different. The ratio of the pipe embedment $e$ to pipe diameter $D$, for nonlinear elastic model is 0.064 , porous elastic model is 0.0575 , Ramberg-Osgood model is 0.075 . It can be drawn the conclusion that the phenomena of the computation compared with the experiment has comparability.

\subsection{Lateral Friction Coefficient}

D.A.Wanger et al. [2] had conducted the monotonic loading and small amplitude oscillative loadings experiment, the lateral resistance coefficient of the latter is 0.888 , which far exceeded the Coulomb friction coefficient 0.7. Our results are as follows: for nonlinear elastic model, the average value using semi-dynamic method is 0.78 ; for Ramberg-Osgood model is 0.897 , the reason is that the effect of the plastic deformation is considered, which result in large deformation and lateral resistance coefficient. The average value of the hydrodynamic experiment [18] is 0.83 , our computational value for porous elastic model is 0.802 , the reason is that in this model, the effect of the pore water is considered. (see Fig. 12)

Where, $\gamma$-buoyant unit weight of soil.

\section{CONCLUSIONS}

1) The pipe/soil interaction upon the untrenched submarine pipeline is for the first time simulated numerically by using the ABAQUS program and dynamic method.

2) In this paper, three different kinds of model are adopted, such as Duncan-Chang nonlinear elastic model, porous elastic model, Ramberg-Osgood models.

3) Three model's results (penetration, soil lateral mounding, resistance coefficient) have differences, but are closer to each other, and in the range of the experimental results, which demonstrates that the computation of pipe/soil interaction is feasible. In a word, the nonlinear elastic model is suitable for the soil that plastic deformation can be ignored; porous elastic model can is suitable for the soil that pore water should be considered, but in fact, this model is in accordance with the actual conditions; Ramberg-Osgood model is suitable for the soil that plastic deformation should be considered.

4) According to the pipe/soil interaction analysis, the results may provide a helpful tool for the engineering practice of pipeline on-bottom stability design.

\section{ACKNOWLEDGEMENT}

The project supported by the National Science Natural Science Foundation of China (19772057) and by the Chinese Academy of Sciences (KZ951-A1-405-01).

\section{CONFLICTS OF INTEREST}

The authors confirm that this article content has no conflicts of interest.

\section{REFERENCES}

[1] H. Brennodden, O. Sveggen, D.A. Wagner, and J. D. Murff, "Fullscale pipe-soil interaction tests". OTC Paper 5-8 May, Huston, Texas 5338, 1986.

[2] D.A. Wanger, J.D. Murff, and H. Brennodden, "Pipe-Soil Interaction Model”, Proceedings of Nineteenth Annual Offshore Technology Conference", paper OTC, 5504, pp. 181-190, 1987.

[3] A.C. Palmer, J. Steenfelt, J.O. Steensen-Bach and V. Jacobson, "Lateral Resistance of Marine Pipelines on Sand", Proceedings of $20^{\text {th }}$ Annual Offshore Technology Conference, Paper OTC, 5853 pp 399-408, 1988.

[4] D. W.Allen, W.F. Lammert, "Submarine Pipeline On-Bottom Stability: Recent AGA Research", Proceedings of $21^{\text {st }}$ Annual Offshore Technology Conference, Paper OTC 6055, vol. 3, pp 121$132,1989$.

[5] H. Brennodden, J.T. Lieng, T. Sotberg, and R.L.P. Verley. "An energy-based pipe-soil interaction model”, OTC paper 6057, 1989.

[6] R.L.P. Verley, "Break-Out Soil Resistance for a Pipeline Partially Buried in Sand", Proceedings of the $9^{\text {th }}$ OMAE Conference, Houston, pp 121-25, 1990.

[7] Det norske Veritas, "On-bottom stability design of submarine pipeline”, Recommended Practice. E305, 1988.

[8] G. Xiaoyun, G. Fu-ping, and P. Qun, "Wave-soil-pipe coupling effect upon submarine pipeline on-bottom stability”. Acta Mech. Sinica (English Ser), vol. 17 , no 1, pp86-96, 2001.

[9] G. fuping, G. xiaoyun, and P. Qun, "Experimental study on submarine pipeline's instability", Chin. J. Geotech. Eng., vol. 22, pp 304-308, 2000, (in chinese).

[10] C.G. Lyons, "Soil Resistance to Lateral Sliding of Marine Pipelines", Proceedings of Fifth Annual Offshore Technology Conference, Paper OTC1876, pp 479-484, 1973.

[11] C.C. Mei, and M.F. Foda, "Wave-induced Stresses around a Pipe laid on a Poro -elastic Seabed". Geotechnique, vol. 31, 509-517, 1981. 
[12] Y. Bai, B.A. Ose, P.R. Nystrom, and P.A. Damsleth, "A fininteElement Model for In-Situ Behavior Offshore Pipelines On Uneven Seabed and Ins Application to On-Bottom Stability", Proc. $9^{\text {th }}$ International Offshore and Polar Engineering Conference, vol. II pp 132-140, 1999.

[13] G. Fu-ping, D.S. Jeng, and Y.X. WU, "Improved Aanlysi Method for Wave-Induced Pipeline Stability on Sandy Seabed", J. Transport. Eng-ASCE, vol. 132 (7): pp 590-596, 2006.

[14] Fu-Ping Gao, S. Yan, B. Yang, and Y. Wu, "Ocean currentsinduced pipeline lateral stability on sandy seabed", J. Eng. MechASCE, vol. 133, no, 10: pp. 1086-1092, 2007.
[15] L. Jing, L. I. Minggao, "Study on Interaction between Submarine Buried Pipeline and Porous Elastic Seabed", Water Resour. Power, vol. 27, no. 5, pp. 159-162, 2009.

[16] HKS. Inc. ABAQUS/Standard User's Manual, version 6.6, USA: HKS. International 2008

[17] J.R. Hale, W.F. Lammert and D.W. Allen, "Pipeline On-bottom Stability Calculations: Comparison of two state-of -the art methods and pipe-soil Verification", Proceedings of $23^{\text {rd }}$ Annual Offshore Technology Conference, Paper OTC 6761: pp. 567-581, 1991.

[18] G. Fu-ping, "Experimental study on the pipeline's on-bottom stability under the wave", Doctorial Disertation, Chinese Acadamy of Sciences, China, 2000. (In Chinese).

(c) Yanrong and Yubiao; Licensee Bentham Open.

This is an open access article licensed under the terms of the Creative Commons Attribution Non-Commercial License (http://creativecommons.org/licenses/by-nc/3.0/) which permits unrestricted, non-commercial use, distribution and reproduction in any medium, provided the work is properly cited. 